\title{
A GINÁSTICA ARTÍSTICA NA PROPOSTA CURRICULAR PARA A EDUCAÇÃO FÍSICA EM SÃO PAULO
}

\author{
Letícia Bartholomeu de Queiroz Lima \\ Universidade de São Paulo, São Paulo, São Paulo, Brasil \\ Paulo Carrara \\ Universidade de São Paulo, São Paulo, São Paulo, Brasil \\ Luiz Henrique Duarte \\ Universidade de São Paulo, São Paulo, São Paulo, Brasil \\ Douglas de Almeida Cipriano \\ Faculdades Metropolitanas Unidas, São Paulo, São Paulo Brasil \\ Myrian Nunomura \\ Universidade de São Paulo, São Paulo, São Paulo, Brasil
}

\section{Resumo}

O objetivo do presente trabalho foi analisar os Cadernos de Educação Física do Estado de São Paulo, especificamente, com enfoque para o conteúdo de Ginástica Artística. O procedimento metodológico utilizado foi a análise temática (SEVERINO, 1996) dos documentos. Os temas destacados, analisados e discutidos foram as características e os fundamentos da Ginástica Artística. Nos resultados são apresentadas sugestões para a aplicação das tarefas exemplificadas nas aulas, com mais detalhes e relacionadas aos fundamentos da Ginástica Artística. Isto poderá facilitar o trabalho do professor em dois aspectos: oferecer maior nível de motivação e elevar a autoestima dos praticantes por meio de subsídios para o desenvolvimento coerente, gradual e prazeroso da Ginástica Artística.

Palavras-chave: Ginástica. Desenvolvimento Infantil. Ensino.

- O presente trabalho não contou com apoio financeiro de nenhuma natureza para sua realização. 


\section{Iintrodução}

Os Cadernos de Educação Física fazem parte da Proposta Curricular da Secretaria de Educação do Estado de São Paulo e é direcionada à rede pública estadual de ensino, mas, também é modelo adotado em algumas instituições privadas. Eles visam oferecer aos professores uma base de conhecimentos e competências, a fim de orientar o desenvolvimento dos conteúdos em uma linha comum de atuação pedagógica. A partir desse objetivo, houve o esforço de promover entre os professores a atitude reflexiva acerca dos desafios sociais, culturais e profissionais observados na sociedade contemporânea.

Este olhar para além da prática da Educação Física Escolar (EFE), que tinha como único objetivo de melhorar as capacidades físicas e esportivas, teve início em meados da década de 1980. As discussões se desenrolaram até meados da década de 1990 (DARIDO, 2001). A partir da segunda metade da década de 1990, a interpretação do papel da EFE começou a ter outro significado. Em 1998 foram publicados os Parâmetros Curriculares Nacionais da Educação Física (PCNs), documento pioneiro na compreensão do aluno como um cidadão atuante na sociedade.

Assim, foi proposto um direcionamento do ensino da EFE focado na formação de um educando autônomo e consciente, capaz de desenvolver o aluno em seus aspectos físicos, cognitivos e sócio-afetivos (BRASIL, 1998). Dessa maneira, os PCNs se estabeleceram como documento referencial para políticas educacionais na área da EF. Os conteúdos desenvolvidos nas aulas de EFE se diversificaram e incluíram a prática de lutas, ginásticas, danças e jogos diversos.

Nessa perspectiva, uma década após a elaboração dos PCNs, a Proposta Curricular no Estado de São Paulo enfoca o desenvolvimento de seus conteúdos baseados na cultura corporal de movimento (SÃO PAULO, 2009). Assim, o conhecimento associado ao uso do corpo pelo aluno é respeitado e relaciona, dinamicamente, a cultura de movimento ao conteúdo desenvolvido pelo professor de EFE. O resgate da cultura corporal é extremamente valorizado e não seria em vão, pois a retomada do potencial motor de cada aluno contribui, progressivamente, para o autoconhecimento de seu corpo e de suas possibilidades em busca de autonomia.

Ao observarmos as possibilidades de desenvolvimento do conteúdo previamente relacionado nos PCN's, percebemos que a ginástica pode contribuir significativamente para a autonomia dos alunos (GERLING, 2009). Do ponto de vista dos referenciais teóricos, a ginástica foi resgatada como forma de conhecimento amplo do corpo (SOARES, 1996). Assim, o conteúdo de Ginástica Artística (GA) escolar, proposto nos Cadernos de Educação Física, deveria destacar e relacionar a experiência prévia dos alunos em diversas situações cotidianas e espontâneas à modalidade. Entretanto, algumas particularidades da GA e o direcionamento de determinadas atividades devem ser enfatizadas para os professores. Pois, muitas vezes, não há o aprofundamento satisfatório nas disciplinas Ginásticas nos cursos superiores de formação (SCHIAVON; NISTA-PICCOLO, 2007).

Além disso, também não há um sistema de formação, inicial ou continuada, específica para os profissionais trabalharem com a GA (NUNOMURA, 2004; NUNOMURA; CARBINATTO; CARRARA, 2013). E, é provável que muitos professores não se sintam encorajados a desenvolver o conteúdo da GA por não se perceberem aptos frente às diversidades de habilidades e progressões, ou por acreditarem que seja uma atividade de risco (NISTA-PICCOLO, 2005; NUNOMURA, 2004).

A partir do exposto, a leitura dos cadernos levantou algumas indagações: qual o conteúdo de GA apresentado nos cadernos e a adequação da proposta para o contexto da escola? Mediante tais 
questionamentos, a presente pesquisa objetivou analisar os Cadernos de Educação Física do Estado de São Paulo, com foco para o conteúdo de Ginástica Artística, apresentando sugestões para a aplicação das tarefas exemplificadas nas aulas.

\section{Método}

Para responder aos questionamentos citados anteriormente, realizamos a leitura dos cadernos do professor da Secretaria de Educação do estado de São Paulo e selecionamos o volume com o conteúdo de GA (SÃO PAULO, 2009). Com a intenção de analisar e aprimorar as propostas curriculares, particularmente sobre o conteúdo da GA na escola, procedeu-se à análise documental sobre a referida proposta.

Como método de investigação, apoiamo-nos nas diretrizes para a leitura, análise e interpretação do documento (SEVERINO, 1996), em que no primeiro momento realiza-se uma análise textual, ou seja, uma abordagem geral e superficial como preparação leitura. A partir de então, procedemos a compreensão do conteúdo do texto, a fim de identificar as proposições e as ideias fundamentais que nem sempre estão explícitas (análise temática). Em seguida, buscamos interpretar as ideias e identificar os principais problemas e contradições, em uma revisão crítica.

Esta revisão crítica está direcionada à problemática levantada neste trabalho (SOUZA JÚNIOR, 2010), principalmente, a relação entre a didática e a aplicabilidade da Ginástica pelo professor de EF na escola. Assim, os temas emergentes, a partir da leitura e respectiva análise foram as Características, os Fundamentos e a Segurança na GA.

Apresentamos e discutimos os aspectos positivos e negativos do referido conteúdo e propomos direcionamentos e sugestões para algumas modificações, com o intuito de contribuir com a divulgação de informações e conhecimento e apoiar a atuação do profissional no contexto educacional.

\section{Resultados e discussão}

Características da Ginástica Artística Escolar

Os conteúdos sobre as características da GA escolar estão apresentados no Quadro 1.

Quadro 1 - Características da Ginástica Artística Escolar.

\begin{tabular}{|c|c|c|c|}
\hline Atividade proposta & Pontos positivos & Pontos negativos & Sugestões \\
\hline $\begin{array}{l}\text { Caderno } \\
\text { professor: situação de } \\
\text { aprendizagem } \mathbf{1} \text { (p. } \\
\text { 15) } \\
\text { Etapa } 3 \text { - eu e meus } \\
\text { colegas... desafios } \\
\text { para saltar: "pular } \\
\text { carniça" também } \\
\text { conhecida como "pular } \\
\text { sela" realizada em } \\
\text { duplas, trios ou } \\
\text { quartetos, o "duro- }\end{array}$ & $\begin{array}{l}\text { Estimula atitudes de } \\
\text { cooperação, interação, } \\
\text { confiança entre os pares e } \\
\text { o fortalecimento dos } \\
\text { membros inferiores para os } \\
\text { movimentos ginásticos. }\end{array}$ & $\begin{array}{l}\text { Apresentam mais } \\
\text { atividades relacionadas } \\
\text { à prova de salto, pois } \\
\text { nesta etapa aborda } \\
\text { também a prova de } \\
\text { solo. }\end{array}$ & $\begin{array}{l}\text { Utilizar figuras específicas } \\
\text { com sequencias para } \\
\text { ilustrar ao professor as } \\
\text { prova de salto e solo, bem } \\
\text { como apresentar exercícios } \\
\text { básicos de solo, que } \\
\text { estejam adequados ao } \\
\text { potencial dos alunos, por } \\
\text { exemplo, rolamentos, } \\
\text { estrelas e reversões. } \\
\text { Ensinar as diversas } \\
\text { possibilidades }\end{array}$ \\
\hline
\end{tabular}




\begin{tabular}{|c|c|c|c|}
\hline mole" com "pula sela". & & & aterrissagens. \\
\hline $\begin{array}{l}\text { Caderno do professor: } \\
\text { Situação } \\
\text { aprendizagem } 1 \text { (p.15) } \\
\text { Etapa } 4 \text { - eu e meus } \\
\text { colegas... desafios de } \\
\text { equilíbrio: amarelinha, } \\
\text { mamãe da rua e } \\
\text { atividade com música } \\
\text { (equilíbrio). }\end{array}$ & $\begin{array}{l}\text { Resgate cultural das } \\
\text { brincadeiras da infância e } \\
\text { possibilidade de prática } \\
\text { coletiva na modalidade } \\
\text { que, essencialmente, tem } \\
\text { características individuais. } \\
\text { Retoma diversos conceitos } \\
\text { e exercícios trabalhados } \\
\text { durante as aulas, e tenta } \\
\text { demonstrar o que } \\
\text { realmente foi aprendido } \\
\text { durante as aulas. }\end{array}$ & \begin{tabular}{lr} 
Poucas atividades & que \\
estimulam & $\mathrm{e}$ \\
desenvolvem & $\mathrm{a}$ \\
capacidade & $\mathrm{de}$ \\
equilíbrio e relacionado \\
\multicolumn{2}{l}{ à prova de trave. }
\end{tabular} & $\begin{array}{l}\text { Diversificar as atividades } \\
\text { que estimulam } \\
\text { desenvolvem a capacidade } \\
\text { de equilíbrio sem e com a } \\
\text { utilização de outros } \\
\text { materiais além do banco } \\
\text { sueco (apesar de ser muito } \\
\text { benéfico nestas } \\
\text { atividades), como linhas } \\
\text { no chão que demarcam o } \\
\text { espaço da trave. }\end{array}$ \\
\hline 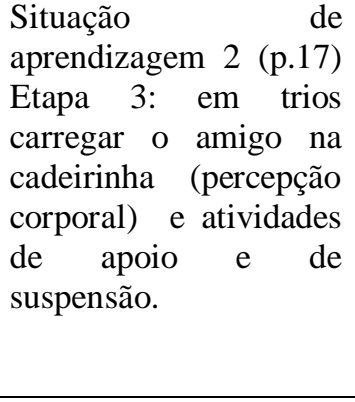 & $\begin{array}{l}\text { Trabalho em grupo que } \\
\text { estimula a organização da } \\
\text { tarefa, a cooperação, a } \\
\text { responsabilidade e a } \\
\text { capacidade força. }\end{array}$ & \begin{tabular}{lr}
\multicolumn{3}{c}{ Sem definição de apoio } \\
e de suspensão. \\
Utilização r de \\
movimentos complexos \\
no início, romo \\
deslocamento r em \\
esquadro.
\end{tabular} & $\begin{array}{l}\text { Definir apoio e suspensão. } \\
\text { Utilizar outras atividades } \\
\text { de apoios variando-os } \\
\text { gradativamente, como } \\
\text { quatro, três e dois apoios. } \\
\text { Orientar bem os alunos } \\
\text { para a tarefa de transportar } \\
\text { uns aos outros, pois a } \\
\text { situação em altura sempre } \\
\text { envolve risco de queda. }\end{array}$ \\
\hline $\begin{array}{l}\text { Etapa } 4 \quad(\mathrm{p} .19): \\
\text { reconhecendo os gestos } \\
\text { e os movimentos } \\
\text { característicos da GA. }\end{array}$ & $\begin{array}{l}\text { Análise e reflexão crítica } \\
\text { dos movimentos, retomada } \\
\text { dos conteúdos aprendidos. }\end{array}$ & $\begin{array}{l}\text { Utilizar este tipo de } \\
\text { estratégia com mais } \\
\text { frequência, pois foi } \\
\text { constatada somente } \\
\text { nesta situação de } \\
\begin{array}{lr}\text { aprendizagem } & \text { em } \\
\text { particular. } & \end{array}\end{array}$ & $\begin{array}{l}\text { Utilizar esta atividade com } \\
\text { os outros conteúdos, ou em } \\
\text { outras situações de } \\
\text { aprendizagem. } \\
\text { Por exemplo, o jogo de } \\
\text { adotar posições corporais } \\
\text { (grupada, carpada, } \\
\text { afastada). }\end{array}$ \\
\hline $\begin{array}{l}\text { Etapa } 2 \text { (p.29): } \\
\text { execução e análise dos } \\
\text { elementos que facilitam } \\
\text { e dificultam a execução } \\
\text { corretar dos } \\
\text { movimentos da GA em } \\
\text { grupos. }\end{array}$ & $\begin{array}{l}\text { Reflexão sobre } \\
\text { capacidades físicas } \\
\text { diferenças de biótipo entre } \\
\text { meninos e meninas. } \\
\text { Autoavaliação. }\end{array}$ & $\begin{array}{l}\text { Descrição e imagem } \\
\text { incorreta de elementos, } \\
\text { como o esquadro e a } \\
\text { vela. }\end{array}$ & $\begin{array}{l}\text { Exemplificar que a figura } \\
\text { não é o movimento } \\
\text { correto, mas parte do } \\
\text { processo de aprendizagem } \\
\text { do mesmo. } \\
\text { Especificar os fatores que } \\
\text { dificultam ou facilitam a } \\
\text { execução desses elementos }\end{array}$ \\
\hline
\end{tabular}

A GA apresenta uma variedade de movimentos que possibilita ampla experiência corporal. É por meio dessas experiências que os alunos têm a oportunidade de ampliar o repertório motor e de desenvolver habilidades sociais como a responsabilidade, o respeito e a cooperação (GERLING, 2009; SCHIAVON; NISTA-PICCOLO, 2007).

Embora a GA seja um esporte individual, o relacionamento entre os alunos durante a prática influencia a conduta uns dos outros. Os alunos podem agir, criar, demonstrar e cooperar, enquanto todos ajudam mutuamente. Eles podem avaliar, apreciar como espectadores e se organizar na distribuição de tarefas (LEGUET, 1987). Algumas atividades propostas no Caderno do Professor propiciam o desenvolvimento desses aspectos citados pelo autor, que favorecem o trabalho em grupo. 
Há poucos locais de prática com infraestrutura que inclui todos os aparelhos oficiais, devido ao custo elevado. Uma das razões para que a ginástica praticamente inexista nas escolas são, entre outras, problemas com a disponibilidade de materiais (SCHIAVON; NISTA-PICCOLO, 2007). Entretanto, alguns materiais podem ser adaptados (SCHIAVON, 2003), pois não há necessidade daqueles sofisticados e oficiais para a prática escolar, mas que ofereçam segurança aos alunos (SCHIAVON; NISTA-PICCOLO, 2007). O Caderno do Professor poderia indicar obras como a da autora citada, em que há mais esclarecimentos sobre os procedimentos de construção e de utilização de aparelhos auxiliares, o que poderia incentivar os profissionais a ensinarem a modalidade.

Ao trabalhar a GA na escola, é importante que o professor tenha conhecimento prévio dos fundamentos básicos da modalidade (NUNOMURA; CARBINATTO; CARRARA, 2013), pois os diferentes tipos de ações motoras que compõem a GA exigem uma técnica característica (KOREN, 2004). Caso o professor utilize somente o material apresentado nos Cadernos, ele poderá encontrar problemas para aplicar o conteúdo proposto. E assim, as atividades poderiam dificultar a compreensão e o desenvolvimento dos alunos na GA.

Além disso, a eventual falta de familiarização e de preparação dos alunos no ensino fundamental prejudica ainda mais o desenvolvimento das atividades, pela base motora insuficiente para realizar movimentos específicos da modalidade. Assim, faz-se necessário um processo gradativo de aprendizagem dos movimentos, em que o aumento da complexidade está condicionado à qualidade dos movimentos anteriores (ARAÚJO, 2012; CARRASCO, 1982); como também a utilização de uma linguagem mais simples, que poderia facilitar a compreensão das descrições e termos técnicos.

A utilização correta da nomenclatura e da descrição dos movimentos no processo de ensinoaprendizagem é muito benéfica e importante. O fato auxilia na caracterização dos elementos ginásticos e possibilita, também, a abordagem de outros conceitos que complementam o conteúdo principal, entre eles de física, de anatomia, de fisiologia e de biomecânica.

Na situação 01 (um), no Caderno do Professor (p.14), a atividade retoma diversos conceitos e exercícios trabalhados durante as aulas. Há a tentativa de demonstrar o que foi aprendido durante as aulas, mas, poderiam também ser requeridas descrições dos exercícios, além da demonstração. Acreditamos que a descrição possibilita a inclusão daqueles com habilidades motoras menos desenvolvidas. Na atividade de avaliação desta etapa sugere-se, também, que os conhecimentos dos alunos sejam relacionados com imagens, movimentos e situações do cotidiano como outra estratégia para a avaliação. A situação 02 (dois), etapa dois (p.17), utilizou adequadamente a associação entre os exercícios realizados até o momento por meio da elaboração de "séries", ou seja, sequências de exercícios. Essa característica assemelha-se muito ao que os alunos poderiam visualizar em campeonatos oficiais, e tem potencial para motivar a prática e pode servir de complementação entre os próprios exercícios.

O conhecimento dos elementos específicos da GA escolar tem como objetivo a aproximação, provavelmente para a maioria dos alunos, a este novo universo, motivando-os para a prática e a procura de novos conhecimentos a partir dos conteúdos legítimos da modalidade. As atividades sugeridas insistem na assimilação de todos os movimentos da GA por meio de alguma atividade cotidiana ou brincadeira infantil. Isso não é sempre possível, pois existem exercícios que são específicos da modalidade, o que não diminui sua importância como experiência motora e tampouco como possibilidade de prática. 
O conteúdo desenvolvido nos Cadernos promove a Cultura Corporal de Movimento e associa o conhecimento prévio do aluno à especificidade e ao conteúdo da GA. Isto pode facilitar aqueles alunos que já têm uma gama de vivências e, então, acrescentam conhecimento ao seu repertório. Entretanto, não são todas as crianças que possuem esse conhecimento prévio, o que pode dificultar ou até desestimular o professor em abordar o conteúdo nesta perspectiva. Além do mais, todos os exercícios desenvolvidos não são passíveis de analogias às brincadeiras e aos movimentos previamente vividos pelas crianças e, também, essas vivências variam consideravelmente no contexto nacional.

Fundamentos e possibilidade de prática da Ginástica Artística

Os conteúdos referentes ao tema fundamentos da GA são apresentados no Quadro 2.

Quadro 2 - Fundamentos da Ginástica Artística.

\begin{tabular}{|c|c|c|c|}
\hline lade & Pontos Positivos & Pontos Negativos & Sugestões \\
\hline $\begin{array}{l}\text { Caderno do } \\
\text { professor: } \\
\text { Apresentação } \\
\text { de quadro com } \\
\text { informações } \\
\text { básicas sobre a } \\
\text { GA (p.12) }\end{array}$ & 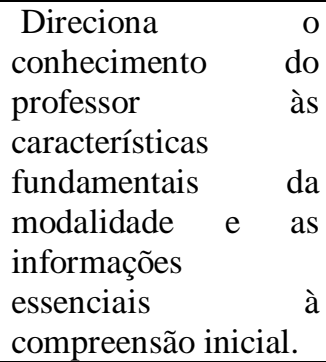 & $\begin{array}{lr}\text { O quadro se apresenta } \\
\text { incompleto, } & \text { com } \\
\text { informações superficiais. } \\
\text { Os autores } \\
\text { desenvolvem que } \\
\text { fundamentos citados não } \\
\text { foram referenciados. }\end{array}$ & $\begin{array}{l}\text { Cada informação poderia conter uma } \\
\text { descrição ou imagem que facilitasse a } \\
\text { compreensão dos termos abordados. } \\
\text { Alguns exemplos são oferecidos na } \\
\text { p.13, mas as imagens não seguem } \\
\text { uma lógica. A organização das } \\
\text { informações, realizada na p.12, está } \\
\text { bem clara, o que poderia servir como } \\
\text { padrão. }\end{array}$ \\
\hline $\begin{array}{l}\text { "Depois, peça } \\
\text { aos alunos que } \\
\text { realizem } \\
\text { diferentes } \\
\text { saltos, giros, } \\
\text { corridas, } \\
\text { rolamentos, } \\
\text { nos planos } \\
\text { alto, médio e } \\
\text { baixo." (p.15) }\end{array}$ & $\begin{array}{lr}\text { Esta atividade é um } \\
\text { ótimo ponto de } \\
\text { partida } \\
\text { relacionar } \\
\text { conhecimento } \\
\text { declarativo } \\
\text { alunos (demonstrado } \\
\text { na atividade anterior) } \\
\text { com alguns } \\
\text { direcionamentos } \\
\text { técnicos de gestos } \\
\text { específicos da GA. }\end{array}$ & $\begin{array}{l}\text { Faltou ilustrar o ambiente } \\
\text { (qual a altura dos planos } \\
\text { alto, médio e baixo), } \\
\text { orientar para a segurança, } \\
\text { o espaço e a ajuda manual. }\end{array}$ & $\begin{array}{l}\text { Nesta parte, há aleatoriedade na } \\
\text { apresentação das informações sobre } \\
\text { os movimentos, como no trecho: } \\
\text { "Durante a vivência, lance ideias e } \\
\text { dicas para orientar os movimentos..." } \\
\text { Deveriam ser apresentadas } \\
\text { sequencias pedagógicas para a } \\
\text { realização dos exercícios. }\end{array}$ \\
\hline $\begin{array}{l}\text { Etapa 3 - } \\
\text { Carregando } \\
\text { meus } \\
\text { colegas... ou } \\
\text { melhor, } \\
\text { suspendendo } \\
\text { meus amigos: } \\
\text { "Balanço nas } \\
\text { barras... } \\
\text { evidenciando } \\
\text { o movimento } \\
\text { articular de } \\
\text { retroversão e } \\
\text { anteversão" }\end{array}$ & $\begin{array}{l}\text { Oferece a } \\
\text { possibilidade de } \\
\text { adaptar os aparelhos } \\
\text { oficiais à condição da } \\
\text { realidade das aulas de } \\
\text { EFE. Agregam-se } \\
\text { elementos não muito } \\
\text { comuns às práticas da } \\
\text { GA escolar, como } \\
\text { deslocamentos sobre } \\
\text { as mãos e balanços, } \\
\text { tanto em suspensão } \\
\text { como em apoio. }\end{array}$ & $\begin{array}{l}\text { Alguns termos trabalhados } \\
\text { na descrição dos exercícios } \\
\text { não são apresentados } \\
\text { adequadamente } \\
\text { professor, por exemplo: } \\
\text { "movimento articular de } \\
\text { retroversão e anteversão" } \\
\text { (p.18). }\end{array}$ & $\begin{array}{l}\text { Tanto a descrição dos exercícios } \\
\text { quanto o detalhamento das situações } \\
\text { de aprendizagem, seja em relação ao } \\
\text { espaço físico ou ao material utilizado, } \\
\text { poderiam oferecer mais informações } \\
\text { ao professor que, muitas vezes, não } \\
\text { tem experiência suficiente em termos } \\
\text { tão específicos. Isto poderia gerar } \\
\text { mais autoconfiança e segurança em } \\
\text { ministrar esses conteúdos, além de } \\
\text { evitar possíveis acidentes. }\end{array}$ \\
\hline
\end{tabular}




\begin{tabular}{|c|c|c|c|}
\hline (p.18). & & & \\
\hline $\begin{array}{l}\text { Etapa } 4 \text { (p.19): } \\
\text { reconhecendo } \\
\text { os gestos e os } \\
\text { movimentos } \\
\text { característicos } \\
\text { da GA. }\end{array}$ & $\begin{array}{l}\text { Retoma diversos } \\
\text { conceitos e exercícios } \\
\text { desenvolvidos } \\
\text { durante as aulas, o } \\
\text { que reforça o } \\
\text { aprendizado. }\end{array}$ & Sem observações. & $\begin{array}{l}\text { Para complementar esta atividade, } \\
\text { poderiam ser requeridas descrições } \\
\text { dos exercícios, e não somente } \\
\text { demonstração, pois há possibilidade } \\
\text { de excluir aqueles menos habilidosos. }\end{array}$ \\
\hline $\begin{array}{l}\text { Situação de } \\
\text { aprendizagem } \\
\mathbf{4}(\mathbf{p . 2 7}) \\
\text { Etapa 1: } \\
\text { explicando as } \\
\text { habilidades da } \\
\text { GA. }\end{array}$ & $\begin{array}{lr}\text { Relacionam } & \text { as } \\
\text { habilidades da } & \text { GA } \\
\text { com os movimentos } \\
\text { articulares, o } & \text { que } \\
\text { promove } & \text { o } \\
\text { conhecimento } & \text { do } \\
\text { corpo, de suas partes } \\
\text { e de } & \text { suas } \\
\text { funcionalidades } & \text { e } \\
\text { limitações. } & \\
\text { Fator de motivação. }\end{array}$ & $\begin{array}{l}\text { Utilização de algumas } \\
\text { imagens de movimentos } \\
\text { complexos executados por } \\
\text { atletas olímpicos, o que } \\
\text { pode confundir os } \\
\text { praticantes em sua } \\
\text { realidade escolar. }\end{array}$ & $\begin{array}{l}\text { A utilização imagens de movimentos } \\
\text { que os alunos vivenciaram durante as } \\
\text { aulas poderia facilitar a relação } \\
\text { proposta nesta etapa. } \\
\text { Caso haja recursos para fotografar ou } \\
\text { filmar os próprios alunos e mostrá- } \\
\text { los como forma de avaliação. } \\
\text { Trabalhar o estilo de ensino } \\
\text { reciprocidade, em que o aluno } \\
\text { interage com o professor e com os } \\
\text { outros alunos como agente ativo do } \\
\text { processo de ensino-aprendizagem. }\end{array}$ \\
\hline
\end{tabular}

A ginástica pode ser praticada com enfoque competitivo, formativo ou recreativo, dependendo de seus objetivos e finalidades, o qual influenciará a abordagem do professor e o conteúdo, além da própria didática (SAWASATO; CASTRO, 2006). O aspecto competitivo da GA é apenas uma das abordagens que o professor pode adotar para a modalidade, mas, essa não deve ser a referência da escola (SCHIAVON; NISTA-PICCOLO, 2007). No ambiente escolar a abordagem mais indicada seria a GA formativa, pois é necessário adequação e coerência com o trabalho realizado pela EF na escola, que busca educar e formar a criança em seus aspectos afetivo, cognitivo e motor (DARIDO, 2001). É possível observar profissionais que limitam a GA apenas a sua vertente competitiva, afastando-a do ambiente escolar, fato que poderia estar relacionado a lacunas no processo de formação (SCHIAVON; NISTA-PICCOLO, 2007).

A ginástica poderia ser oferecida também em outras séries letivas e, paralelamente, a outras modalidades e com maior duração. Para isso, os professores deveriam ser capazes de explicar às crianças sobre as diferentes possibilidades de práticas da GA, competitiva ou formativa, de modo que elas compreendam os objetivos durante as aulas de EF na escola.

A adaptação aos aparelhos e aos movimentos é ponto fundamental para desenvolver o conteúdo e proporcionar segurança aos alunos. Porém, parece-nos que a proposta principal dos Cadernos é fazer o professor "conhecer" aqueles movimentos que as crianças conseguem realizar durante as aulas. Como evidência, podemos citar a proposta "peça aos alunos para realizar" conforme as capacidades de cada um e sua cultura corporal. Deveriam ser propostos para todos os alunos os fundamentos básicos, a adaptação aos aparelhos e a progressão dos movimentos conforme o domínio corporal individual (GERLING, 2009).

Independentemente da abordagem, seja competitiva, formativa ou recreativa, a GA é caracterizada em bases motoras comuns, conhecidas como fundamentos da GA. Ao contrário do que muitos professores pensam esses fundamentos não se resumem às habilidades da modalidade, tais como rolamentos, estrelas, saltos mortais, entre inúmeros outros movimentos de diversos níveis de complexidade (SCHIAVON; NISTA-PICCOLO, 2007). 
A apresentação dos fundamentos na literatura foi realizada de maneira distinta por diversos autores, sendo que cada proposta segue uma lógica de organização. Dentre estes fundamentos, podemos destacar as seguintes propostas: "Padrões Básicos da Ginástica" (RUSSELL, 2009), "Famílias" (CARRASCO, 1982) e "Ações Motoras" (LEGUET, 1987). As propostas de divisão do conteúdo da GA, apresentadas por Leguet (1987) e Carrasco (1982), parecem ser aquelas mais adotadas pelos profissionais e acadêmicos no Brasil (NISTA-PICCOLO, 2005; NUNOMURA, 2004).

Os Cadernos utilizam determinadas terminologias e divisão de conteúdos desenvolvidos por alguns autores. No Caderno do professor (p.12), são utilizados os fundamentos de Leguet (1987), mas o autor não é referenciado, o que dificulta o estudo aprofundado caso seja interesse do professor. São citados, também, alguns fundamentos como retroversão e anteversão (p.18) que são utilizados por Carrasco (1982).

Ao observarmos os autores supracitados, verificamos que a organização dos conteúdos da GA baseia-se na semelhança entre as ações motoras dos movimentos. Independentemente da lógica adotada pelos autores para estabelecer os padrões de movimentos da GA, esta organização ajuda o professor a focar na base motora da ginástica para depois ampliar a complexidade dos movimentos por meio da combinação desses padrões de movimentos.

A classificação dos fundamentos por esse prisma oferece ao professor e ao treinador a ideia mais aprofundada das bases de cada elemento. Ao proporcionar aos alunos a prática dos fundamentos da GA, o conteúdo da aula é mais diversificado. Assim, por meio da combinação dos fundamentos, há ampla variedade de movimentos para o aprendizado de habilidades motoras simples ou mais complexas.

Outra atividade sugerida nos Cadernos (p.15 - "peça para os alunos realizar...") não abordava nenhuma situação em que a aterrissagem fosse solicitada. Para Russell (2009) as aterrissagens devem ser o primeiro fundamento a ser aprendido na GA, pois ajudam a garantir a integridade física do praticante, ou seja, a prática mais segura.

Há alguns pontos em que a informação requerida do aluno não foi apresentada plenamente durante as atividades desenvolvidas em sala de aula. Na atividade em que o aluno deve relacionar as imagens com situações de apoio, de suspensão e de equilíbrio, não são fornecidos conhecimentos teóricos suficientes, tanto para o aluno quanto para o professor. No Caderno do professor, não há descrição detalhada do que seja a posição em apoio, em suspensão ou em equilíbrio.

Em outra situação (p.15), são exigidos conhecimentos prévios dos professores para que a atividade ocorra adequadamente, assim como se parte do pressuposto de que o professor tenha domínio sobre a realização técnica do exercício. São apresentadas, também, possibilidades diferenciadas para realizar exercícios e correções técnicas, que aparentam ser aleatórios e que exigem conhecimento prévio do professor, mas que muitas vezes não ocorre. De outro modo, a progressão coerente dos níveis de aprendizado permitiria, tanto ao aluno quanto ao professor, compreender as possibilidades e limitações da prática, o que poderia torná-la mais prazerosa e segura. 


\section{Considerações finais}

Muitas vezes os professores de EF não têm acesso à literatura específica sobre a GA. Assim, os Cadernos elaborados pela Secretaria de Educação do Estado de São Paulo são importantes fontes de consulta para esses profissionais. Este material contém informações sobre o desenvolvimento de atividades específicas, o que facilita a visualização da modalidade no contexto escolar. Entretanto, a partir de nossa análise, percebemos que o conteúdo oferecido pelos Cadernos é somente um ponto de partida para a compreensão satisfatória da GA pelo profissional.

Portanto, a proposta apresenta lacunas às necessidades dos professores, pois poderia haver dificuldade em determinar os movimentos adequados para o grupo de alunos presentes. Os Cadernos poderiam incluir um referencial para auxiliar os professores na escolha do conteúdo específico da GA. A observação inicial, da cultura corporal dos alunos, deve ser bem criteriosa, o que exige do professor familiaridade com os movimentos da GA. Logo, seria interessante que as próximas edições dos Cadernos oferecessem os conteúdos específicos da modalidade de forma mais clara e explicativa ao professor, para possibilitar a melhor aplicabilidade dos conteúdos e da modalidade em si.

Poucos direcionamentos foram sugeridos para estruturar as seções de aulas. Como organizar, por exemplo, uma sequencia pedagógica para aplicar atividades relacionadas ao objetivo da aula e adequá-las às principais atividades propostas. Não esperamos um modelo rígido a ser adotado em cada aula, mas, orientações para a ponderação e a criação das próprias atividades baseadas nas informações fornecidas pelos Cadernos e pela literatura.

O número de alunos e de aparelhos disponíveis é outro ponto importante para a fluência da aula, e que não aparece nos Cadernos. Fica a necessidade de o professor aprofundar os conhecimentos sobre procedimentos de segurança tais como o ambiente e a eventual ajuda manual.

$\mathrm{O}$ conteúdo didaticamente detalhado e aliado à formação continuada do professor auxilia a compreensão e o melhor desenvolvimento dos temas. Refletir e agir de maneira consciente sobre como ensinar a GA em consideração ao ambiente, aos conteúdos práticos, teóricos e ao aluno, permitiria o aprimoramento dos fundamentos, a compreensão do professor sobre a modalidade, os limites de seus alunos e as necessidades de sua atuação.

Um ponto de partida que poderia ser utilizado para a iniciação dos movimentos básicos da GA seria o professor analisar a habilidade que deseja aplicar e responder às seguintes perguntas: quais as principais ações musculares e articulações envolvidas? Qual a amplitude de movimento que essa habilidade exige? Para isto o professor pode realizar uma vivência por meio de movimentos simplificados para conhecer as possibilidades de seus alunos, verificar as capacidades físicas (coordenação motora, força, flexibilidade), a afetividade (medo, insegurança, interesse) e o ambiente (espaço, aparelhos). Os alunos podem apresentar diferenças na cultura corporal de movimentos entre si, ora mais ou menos desenvolvidos. Por fim, depois de estudar a habilidade motora específica, os alunos e o ambiente, o professor planejará sua ação, embasado nos resultados de sua análise e reflexão sobre como, onde e o que ensinar. A condição física e a consciência corporal são fatores básicos para a iniciação da prática de GA. A presença desses fatores em aula deve ocorrer em função da importância deles na execução correta e segura dos movimentos.

Quanto ao planejamento, não há nos Cadernos a ideia de continuidade do conteúdo a ser desenvolvido no programa. Caso houvesse, permitiria ao professor desenvolver mais as atividades 
ou adequar mais aulas, se necessário. E, também, avançar na complexidade das habilidades caso tenha, por exemplo, alunos com mais condições ou equipamentos de melhor qualidade.

A identificação das estruturas da ginástica é um ponto importante e, muitas vezes, esquecida pelo professor. O que acontece é que o aluno sabe realizar o movimento, mas não sabe identificá-lo. É importante retomar diversos conceitos e exercícios trabalhados durante as aulas, a fim de demonstrar o que realmente foi aprendido durante as aulas e as atividades de autoavaliação.

Por fim, poderia haver mais estímulo à reflexão sobre o desenvolvimento dos alunos, a fim de saber como e quando avançar na GA, ou seja, tomar as decisões corretas no momento certo. E, também, haver estímulo à autoavaliação dos professores, atitude importante para despertar a reflexão sobre a própria atuação. Consequentemente, isto pode levar a mudanças positivas e ao aprimoramento da ação do professor.

Os Cadernos contribuem para a formação de um educando autônomo e consciente, capaz de desenvolver o aluno em seus diversos aspectos. Seu conteúdo poderia ser adaptado ao desenvolvimento da modalidade GA para oferecer o entendimento mais amplo aos professores sobre a temática. Sugerimos ainda aos professores, consultar, refletir e aplicar nas aulas as referências literárias presentes nestes Cadernos, buscar a formação continuada (cursos, oficinas, visita às academias de GA e comunicação com professores da área) a fim de estimular uma atuação mais efetiva no universo de possibilidades da GA na EFE.

\title{
ARTISTIC GYMNASTICS CURRICULAR PROPOSAL FOR PHYSICAL EDUCATION IN SÃO PAULO
}

\begin{abstract}
The aim of this essay was to analyze the Physical Education "Cadernos" of São Paulo State, specifically, focusing the Gymnastics contents. The methods procedure was based on thematic analysis (SEVERINO, 1996) of the documents. The themes highlighted, discussed and analyzed were the Gymnastics characteristics and foundations. In the results are presented suggestions for applying the tasks in the classes, with more detailed depicted and gymnastics foundations related. This may make easy the teachers work in two aspects: to offer greater motivation and self-esteem to students through backgrounds for coherent, gradual and pleasant development of gymnastics.
\end{abstract}

Keywords: Gymnastics. Child Development. Teaching.

\section{LA GIMNASIA EN LA PROPUESTA CURRICULAR DE LA EDUCACIÓN FÍSICA DE SÃO PAULO}

\section{Resumen}

El objetivo do presente trabajo fue analizar los "Cadernos" de Educación Física en el Estado de São Paulo, en particular, con enfoque en el contenido de Gimnasia. Lo procedimiento metodológico utilizado fue el análisis temático (SEVERINO, 1996) de los documentos. Los temas señalados, analizados y debatidos fueran las características y los fundamentos de Gimnasia. En los resultados se presentan sugerencias para la realización de las tareas ejempladas en las clases, con más detalle y relacionados con los fundamentos de gimnasia. Esto podría facilitar la labor de los profesores en 
dos aspectos: proporcionar un alto nivel de motivación y elevar la autoestima de los profesionales a través de las subvenciones para el desarrollo coherente, gradual y agradable de la Gimnasia.

Palabras-clave: Gimnasia. Desarrollo Infantil. Enseñanza.

\section{Referências}

ARAÚJO, C. M. Manual de ajudas em ginástica. 2 ed. Várzea Paulista: Editora Fontoura, 2012. 248p.

BRASIL. Secretaria da Educação Fundamental. Parâmetros Curriculares Nacionais. Educação Física, $3^{\circ}$ e $4^{\circ}$ ciclos, v. 07. Brasília: MEC, 1998. 114p.

CARRASCO, R. A atividade do principiante: programas pedagógicos. 4. ed. São Paulo: Editora Manole, 1982. 55p.

DARIDO, S. Os conteúdos da educação física escolar: influências, tendências, dificuldades e possibilidades. Perspectivas em Educação Física Escolar, Niterói, v. 02, n. 01 (suplemento), p. 05-25, 2001.

GERLING, I. Teaching Children's Gymnastics. 2. ed. Maidenhead: Meyer \& Meyer Sport, 2009. 244p.

KOREN, S. A Ginástica vivenciada na escola e analisada na perspectiva da criança. 2004. $203 \mathrm{f}$. Dissertação (Mestrado) - Faculdade de Educação Física, UNICAMP, Campinas, São Paulo, 2004.

LEGUET, J. As ações motoras em ginástica esportiva. São Paulo: Editora Manole, 1987. 227p.

NISTA-PICCOLO, V. L. Pedagogia da Ginástica Artística. In: NUNOMURA, M.; NISTAPICCOLO, V. (Ed.). Compreendendo a ginástica artística. São Paulo: Phorte, 2005. cap. 2, p.2736.

NUNOMURA, M. A Formação dos Técnicos de Ginástica Artística: os modelos internacionais. Revista Brasileira de Ciência e Movimento, Brasília, v. 12, n. 3, p.63-69, 2004.

NUNOMURA, M.; CARBINATTO, M. V.; CARRARA, P. D. Reflexão sobre um programa de formação profissional na ginástica artística. Pensar a Prática, v. 16, n. 2, p.469-483, 2013.

RUSSELL, K. National Coaching Certification Program: Introductory Gymnastics Level 1. Ontario: Gymnastics Canada Gymnastique Publication, 2009. 52p.

SÃO PAULO (Estado) Secretaria da Educação. Caderno do professor: educação física, ensino fundamental $-5^{\mathrm{a}}$ - série, volume 3. São Paulo: SEE, 2009. 32p. 
SAWASATO, Y.; CASTRO, M. A dinâmica da Ginástica Olímpica (GO). In: GAIO, R.; BATISTA, J. (Org). A ginástica em questão: corpo e movimento. Ribeirão Preto: Tecmedd, 2006. cap. 8, p.107-127.

SCHIAVON, L. O projeto “Crescendo com a Ginástica”: uma possibilidade na escola. 2003. 182 f. Dissertação (Mestrado) - Faculdade de Educação Física, UNICAMP, Campinas, São Paulo, 2003.

SCHIAVON, L.; NISTA-PICCOLO, V. L. A ginástica vai à escola. Movimento, v. 13, n. 3, p.131150, 2007.

SEVERINO, A. J. Metodologia do trabalho científico. 20. ed. São Paulo: Cortez,1996. 278p.

SOARES, C. Educação física escolar: conhecimento e especificidade. Revista Paulista de Educação Física, São Paulo, supl. 2, p. 6-12, 1996.

SOUZA JÚNIOR, M; A análise de conteúdo como forma de tratamento dos dados numa pesquisa qualitativa em Educação Física escolar. Movimento, Porto Alegre, v. 16, n. 03, p. 31-49, 2010.

Recebido em: 08/10/2014

Revisado em: 13/05/2015

Aprovado em: 10/06/2015

Endereço para correspondência:

Myrian Nunomura

mnunomur@usp.br

Universidade de São Paulo, Escola de Educação Física e Esporte de Ribeirão Preto.

Av. dos Bandeirantes 3900

Monte Alegre

14040907 - Ribeirão Preto, SP - Brasil 